\title{
LA EXPULSIÓN DE EXTRANJEROS EN EL PACTO INTERNACIONAL DE DERECHOS CIVILES Y POLÍTICOS
}

\section{EXPULSION OF ALIENS IN THE INTERNATIONAL COVENANT ON CIVIL AND POLITICAL RIGHTS}

Fernando ARLETTAZ ${ }^{2}$

SUMARIO: I. Introducción: la expulsión de extranjeros en el derecho internacional. II. Situación general de los extranjeros en el Pacto. III. Límites sustantivos a la expulsión. IV. Reglas formales sobre la expulsión. V. Conclusiones.

RESUMEN: El presente trabajo aborda el tema de la expulsión de extranjeros en el marco del Pacto Internacional de Derechos Civiles y Políticos. Se estudian primeramente algunas cuestiones conceptuales sobre la expulsión de extranjeros en general y se analiza la situación global de los extranjeros en el Pacto. Luego se enfoca la expulsión de extranjeros a la luz del Pacto desde un doble ángulo: el de los límites sustantivos a la expulsión que pueden provenir, por ejemplo, de las normas que protegen la vida, la integridad física o la familia y el de las reglas procedimentales que deben respetarse. Para el estudio se recurre a la actividad interpretativa realizada por el Comité de Derechos Humanos, manifestada tanto a través de sus opiniones generales como de sus decisiones ante comunicaciones individuales. Se menciona también el criterio interpretativo de la Corte Internacional de Justicia.

Palabras clave: extranjeros, Pacto Internacional de Derechos Civiles y Políticos, expulsión.

ABSTRACT: The paper addresses the issue of the expulsion of aliens under the International Covenant on Civil and Political Rights. General aspects of the expulsion of aliens, as well as the situation of aliens under the Covenant, are first studied. Then the paper approaches the expulsion of aliens under the Covenant from a double point of view: the substantive limits to the power to expel an alien (which may come, for example, from the rules that protect life, physical integrity or family) and the procedural rules which must be respected. The paper considers the interpretative activity carried out by the Human Rights Committee, expressed both through its general observations and its individual decisions. It also mentions the interpretative criteria of the International Court of Justice.

Keywords. aliens, International Covenant on Civil and Political Rights, expulsion.

\footnotetext{
${ }^{1}$ Artículo recibido el 5 de noviembre de 2014 y aceptado para su publicación el 21 de junio de 2015

${ }^{2}$ Doctor en sociología jurídica e instituciones políticas por la Universidad de Zaragoza. Investigador del Laboratorio de Sociología Jurídica de la Universidad de Zaragoza
} 


\section{INTRODUCCIÓN: LA EXPULSIÓN DE EXTRANJEROS EN EL DERECHO INTERNACIONAL}

En este trabajo abordaremos el estudio de las reglas sustantivas y formales relativas a la expulsión de extranjeros, contenidas en el Pacto Internacional de Derechos Civiles y Políticos. Según el informe preliminar del relator especial, Maurice Kamto, sobre expulsión de extranjeros, el concepto de expulsión ha de entenderse en un sentido amplio como "el acto jurídico por el cual un Estado obliga a una persona o grupo de personas nacionales de otro Estado a abandonar su territorio". ${ }^{3}$ Esta aproximación inicial debe sin embargo ampliarse para incluir no sólo a los extranjeros que son nacionales de otro Estado, sino también a los apátridas (sin que el concepto en sí mismo prejuzgue sobre la licitud o ilicitud de tales expulsiones). Aunque por supuesto es conceptualmente posible la expulsión de nacionales, no nos ocuparemos de ella aquí. Limitaremos nuestro estudio a la cuestión de la expulsión de extranjeros.

La definición amplia de expulsión que hemos dado incluye distintas categorías más específicas, como la expulsión en sentido estricto, la extradición, etcétera. ${ }^{4}$ La expulsión en sentido estricto es el ejercicio de la facultad de un Estado de exigir a un extranjero que abandone su territorio cuando su presencia continua es contraria a los intereses de ese Estado. ${ }^{5}$

Aunque la expulsión normalmente se identifica con un acto expreso del Estado, ella puede asumir la forma de una expulsión implícita. La expulsión implícita se da en aquellos casos en que un Estado realiza actos, o tolera actos de particulares, que tienden

${ }^{3}$ Kamto, Maurice, Informe preliminar sobre la expulsión de extranjeros, A/CN.4/554, 2005, p. 13.

${ }^{4}$ El proyecto de artículos sobre expulsión de extranjeros recepta una definición más restringida de expulsión, según la cual es "un acto formal o una conducta atribuible a un Estado por el cual un extranjero es compelido a abandonar el territorio de ese Estado; no incluye la extradición a otro Estado, la entrega a una corte o tribunal internacional o la no-admisión de un extranjero a un Estado" (Draft articles on the expulsion of aliens, with commentaries, adopted by the International Law Commission at its sixty-sixth session, in 2014, and submitted to the General Assembly as a part of the Commission's report covering the work of that session [A/69/10], artículo 2.a).

${ }^{5}$ Comisión de Derecho Internacional, Expulsión de extranjeros-Memorando de la Secretaría, 58 periodo de sesiones, A/CN.4/565, párrafo 67. Goodwin-Gill, Guy S., International Law and the Movement of Persons Between States, Oxford, Clarendon Press, 1978, pp. 201 y 206. La expulsión implica la salida del territorio del Estado, y por ello debe distinguirse del desplazamiento interno. 
Esta revista forma parte del acervo de la Biblioteca Jurídica Virtual del Instituto de Investigaciones Jurídicas de la UNAM

a crear un clima que fuerza a los extranjeros a abandonar el territorio, aunque no exista una decisión formal a este respecto. ${ }^{6}$ Es lo que se ha denominado expulsión disfrazada o encubierta. $^{7}$

La expulsión ha de diferenciarse de la denegación de admisión, por la cual un Estado impide entrar a su territorio a un extranjero. Es discutible si el caso del extranjero que ha ingresado al territorio ilegalmente y que luego es obligado a abandonar el mismo debe ser calificado de denegación de admisión o de expulsión. ${ }^{8}$ Por nuestra parte, y por motivos conceptuales, preferimos calificar el caso como de expulsión.

Tanto la expulsión como la denegación de admisión son actos por los que se ordena algo: sea que el extranjero salga del Estado, sea que el extranjero no ingrese a él. Algunos autores usan la expresión deportación para referirse a la realización efectiva de la orden de expulsión ${ }^{9}$ o la denegación de admisión, ${ }^{10}$ o bien, ambas. ${ }^{11}$ A veces se utiliza otra terminología, que por razones de espacio no podemos analizar aquí. ${ }^{12}$

La hipótesis central de este trabajo es que de la interpretación sistemática del Pacto Internacional de Derechos Civiles y Políticos puede obtenerse un conjunto bastante sólido de pautas sobre las reglas aplicables a la expulsión de extranjeros (entendiendo este concepto en sentido amplio). Igualmente, se conjetura que la interpretación del Pacto por el Comité de Derechos Humanos, órgano de control de su efectividad, desgaja una lectura coherente del conjunto de las disposiciones convencionales. Tales

${ }^{6}$ Doehring, Karl, "Aliens, Expulsion and Deportation", en Bernhardt, Rudolf (dir.), Encyclopedia of Public International Law, Amsterdam, Elsevier Science Publishers, vol. 1, 1992, pp. 109-112.

${ }^{7}$ Draft articles on the expulsion of aliens, artículo 10.

${ }^{8}$ Doehring, Karl, op. cit., pp. 109-112.

${ }^{9}$ Ibidem, pp. 109-112.

${ }^{10}$ Goodwin-Gill, Guy S., op. cit., p. 201.

${ }^{11}$ Organización Internacional para las Migraciones, Glosario sobre migración, Ginebra, OIM, 2006, p. 19.

${ }^{12}$ La denegación de admisión es a veces llamada exclusión. También es utilizada la expresión reconducción a la frontera (renvoi, reconduction à la frontière) para referirse a un procedimiento sumario de expulsión. La extradición se diferencia de la expulsión por el hecho de que esta última es una decisión unilateral de un Estado, mientras que la primera requiere la cooperación de dos Estados para hacer efectiva la legislación penal de uno de ellos. La entrega es una forma de traslado de una persona a otro país, en general en el contexto de la investigación de determinado delito, pero al margen de todo procedimiento jurídico reglado. 
Esta revista forma parte del acervo de la Biblioteca Jurídica Virtual del Instituto de Investigaciones Jurídicas de la UNAM www.juridicas.unam.mx

disposiciones tienden a asegurar ciertos derechos de los extranjeros sujetos a expulsión o expulsados, dentro las limitaciones que implica el reconocimiento del estatuto legal disminuido de los extranjeros en relación con los nacionales (estatuto disminuido que el derecho internacional reconoce y que el Pacto recepta).

La facultad de los Estados de expulsar a extranjeros surge de una regla bien establecida en derecho internacional. La existencia de esta regla está ampliamente atestiguada por la doctrina ${ }^{13}$ y la jurisprudencia ${ }^{14}$ internacionales, así como por la jurisprudencia interna de muchos Estados. ${ }^{15}$

${ }^{13}$ Borchard, Edwin M., The Diplomatic Protection of Citizens Abroad or the Law of International Claims, Nueva York, The Banks Law Publishing Co., 1915, p. 48; Preuss, Lawrence, "International Law and Deprivation of Nationality", Georgetown Law Journal, núm. 23, 1934, pp. 250-276; Oda, Shigeru, "The Individual in International Law", en Sørensen, Max (dir.), Manual of Public International Law, Nueva York, St. Martin's Press, 1968, pp. 469-530; Goodwin-Gill, Guy S., op. cit., p. 203; Plender, Richard, International Migration Law, Dordrecht, Martinus Nijhoff Publishers, 1988, p. 459; Quoc Dinh, Nguyen, Droit international public, Paris, Librairie Générale de Droit et de Jurisprudence, 1994, pp. 658-666; Jennings, Robert y Watts, Arthur, Oppenheim's international law, 9a ed., vol. I, 1996, p. 940; Combacau, Jean y Sur, Serge, Droit international public, París, Montchrestien, 1999, pp. 361-374; Remiro Brotóns, Antonio, Derecho internacional, Valencia, Tirant lo Blanch, 2007, pp. 831-843; Díez de Velasco, Manuel, Instituciones de derecho internacional público, Madrid, Tecnos, 2007, pp. 611-617; Pastor Ridruejo, José Antonio, Curso de derecho internacional público y organizaciones internacionales, Madrid, Tecnos, 2012, pp. 235-243.

${ }^{14}$ Corte Internacional de Justicia, Nottebohm case (Liechtenstein v. Guatemala), sentencia (segunda fase) del 6 de abril de 1955; Tribunal Europeo de Derechos Humanos, Moustaquim v. Belgium, sentencia del 18 de febrero de 1991, demanda 12313/86; Tribunal Europeo de Derechos Humanos, Vilvarajah and others v. United Kingdom, sentencia del 30 de octubre de 1991, demandas 13163/87, 13164/87, 13165/87, 13447/87 y 13448/87; Tribunal Europeo de Derechos Humanos, Chacal v. United Kingdom, sentencia del 15 de noviembre de 1996, demanda 22414/93; Tribunal Europeo de Derechos Humanos, Ahmed v. Austria, sentencia del 17 de diciembre de 1996, demanda 25964/94. Tribunal Europeo de Derechos Humanos, Bouchelkia v. France, sentencia del 29 de enero de 1997, demanda 23078/93; Tribunal Europeo de Derechos Humanos, H. L. R. v. France, sentencia del 29 de abril de 1997, demanda 24573/94; Corte Interamericana de Derechos Humanos, Opinión consultiva OC-18/03 Condición jurídica y derechos de los migrantes indocumentados, del 17 de septiembre de 2003; Corte Interamericana de Derechos Humanos, Nadege Dorzema y otros v. República Dominicana, sentencia (fondo, reparaciones y costas) del 24 de octubre de 2012; Corte Interamericana de Derechos Humanos, Vélez Loor v. Panamá, sentencia (excepciones preliminares, fondo, reparaciones y costas) del 23 de noviembre de 2010.

${ }^{15}$ Por citar sólo algunos casos clásicos: United States Supreme Court, Fong Yue Ting v. U.S., 149 US 698 (1892). United States Supreme Court, Nishimura Ekiu v. U.S, 142 US 651 (1892); United States Supreme Court, Harisiades v. Shaughnessy, 342 US 580 (1952); Privy Council, Musgrove v. Chun Teeong Toy, [1891] A.C. 272. 
Es opinión mayoritaria que la expulsión no tiene en sí misma naturaleza de sanción penal, sino que se trata de un acto de carácter administrativo. ${ }^{16}$ Los Estados gozan respecto de la expulsión de un importante margen de discrecionalidad. Sin embargo, la facultad de expulsar extranjeros está sometida a limitaciones emergentes del derecho internacional. $^{17}$

Algunos de estos límites corresponden a un esquema de relaciones interestatales. Así, los Estados, al expulsar a un extranjero están limitados por la prohibición del abuso de derecho, el principio de la buena fe, la prohibición de adoptar medidas arbitrarias, y el trato mínimo debido a los extranjeros. ${ }^{18}$ Igualmente, se ha afirmado que el derecho de expulsar debe ser ejercitado en los límites de su función y propósito, y que está sometido al requerimiento de justificación, aunque el Estado goce de un cierto margen de apreciación al respecto. ${ }^{19}$

Al lado de estas limitaciones propias del contexto de las relaciones interestatales hay otras que emergen del derecho internacional de los derechos humanos. Muchos tratados internacionales en este campo contienen disposiciones que limitan la facultad de los Estados. En ocasiones, algunas normas del derecho internacional de los derechos humanos han adquirido carácter consuetudinario, como sucede con el principio de nonrefoulement, propio del derecho de los refugiados. ${ }^{20}$

\section{SITUACIÓN GENERAL DE LOS EXTRANJEROS EN EL PACTO}

Privy Council, Attorney-General for Canada v. Cain, [1906] AC 542. Privy Council, Johnstone v. Pedlar [1921] 2 AC 262.

${ }^{16}$ Kamto, Maurice, Sexto informe sobre la expulsión de extranjeros, A/CN.4/625.Add.1, 2010, p. 43. GoodwinGill, Guy, op. cit., pp. 238 y 239.

${ }^{17}$ Borchard, Edwin M., op. cit., p. 49; Oda, Shigeru, op. cit., nota 11, p. 482; Goodwin-Gill, Guy S., op. cit., p. 204; Plender, Richard, op. cit., p. 459; Jennings, Robert y Watts, A., op. cit., p. 940; Remiro Brotóns, Antonio, op. cit., pp. 831-843; Díez de Velasco, Manuel, op. cit., pp. 611-617; Pastor Ridruejo, José Antonio, op. cit., pp. 235-243.

${ }^{18}$ Comisión de Derecho Internacional, op. cit., pfo. 201.

${ }^{19}$ Goodwin-Hill, Guy S., op. cit., p. 208.

${ }^{20}$ Ibidem, p. 142. 
Esta revista forma parte del acervo de la Biblioteca Jurídica Virtual del Instituto de Investigaciones Jurídicas de la UNAM

Una rápida lectura del Pacto Internacional de Derechos Civiles y Políticos ${ }^{21}$ permite relevar diferentes categorías de sujetos titulares de derechos con arreglo al mismo. Aunque en la mayoría absoluta de los artículos del Pacto, el sujeto titular del derecho reconocido es toda persona (por ejemplo, artículo 6o. sobre derecho a la vida; artículo 70. sobre prohibición de la tortura; artículo 80. sobre la prohibición de la esclavitud, etcétera), otros artículos se refieren a sujetos más específicos. Así, la libre determinación del artículo 10. se predica de los pueblos, la protección del artículo 23 está orientada a la familia; el artículo 24 está referido a todo niño, y el artículo 27, a las personas pertenecientes a minorías. Como se verá con más detalle a continuación, prácticamente todos estos derechos amparan también a los extranjeros, en la medida por supuesto en que estén reunidos los presupuestos establecidos por el artículo correspondiente (por ejemplo, el artículo 27 protege tanto a nacionales como a extranjeros en la medida en que unos u otros puedan decirse pertenecientes a una minoría).

El Comité de Derechos Humanos se ha referido con detalle a la situación de los extranjeros en dos comentarios generales (además de mencionarlos incidentalmente en otros). Por un lado, en la Observación General Núm. 15, el Comité abordó de forma global la situación de los extranjeros con arreglo al Pacto. ${ }^{22}$ Por otro lado, en la Observación General Núm. 27 el Comité se refirió a la cuestión de la libertad de circulación, $^{23}$ respecto de la cual los extranjeros se encuentran en una situación particular. Además, el Comité ha tenido ocasión de interpretar el Pacto en relación con estos temas en muchas decisiones relativas a comunicaciones individuales. Según ha sostenido el Comité, los extranjeros gozan de todos los derechos reconocidos en el Pacto Internacional de Derechos Civiles y Políticos, salvo aquellos de los que están expresamente excluidos. ${ }^{24}$

\footnotetext{
${ }^{21}$ Pacto Internacional de Derechos Civiles y Políticos, adoptado y abierto a la firma, ratificación y adhesión por la Asamblea General de las Naciones Unidas en su resolución 2200 A (XXI), del 16 de diciembre de 1966. En vigor desde el 23 de marzo de 1976, de conformidad con el artículo 49.

22 Observación General Núm. 15: La situación de los extranjeros con arreglo al Pacto, 27 período de sesiones, HRI/GEN/1/Rev.7 at 159 (1986).

${ }^{23}$ Observación General Núm. 27: Artículo 12 La libertad de circulación, 67 periodo de sesiones, HRI/GEN/1/Rev.7 at 202 (1999).

${ }^{24}$ Observación General Núm. 15, pfos. 1 y 4.
} 
Por un lado, los extranjeros se hallan excluidos de la titularidad de los derechos políticos (artículo 25 del Pacto). Por otra parte, aunque los extranjeros no están totalmente excluidos de la titularidad de las libertades de circulación y de residencia, sí tienen a su respecto importantes límites. Aunque la libertad de circulación "es una condición indispensable para el libre desarrollo de la persona", 25 el Pacto consagra este derecho y el de residencia de modo pleno sólo para los nacionales del Estado en el que vayan a ejercerse.

Así, el derecho a ingresar a un determinado país no corresponde, en principio, a los extranjeros. Según el artículo 12.4 del Pacto, “nadie podrá ser arbitrariamente privado del derecho a entrar en su propio país". Si bien la expresión su propio país es, según el Comité, más amplia que la expresión país de su nacionalidad, sólo en casos muy puntuales en los que exista una fuerte vinculación con el territorio podría una persona invocar un derecho a entrar en un país cuya nacionalidad no posee.

Dado que no existe un derecho protegido por el Pacto a ingresar a un país que no es el propio, tal entrada depende de una autorización de parte del Estado. El Estado puede otorgar su consentimiento a la entrada del extranjero con sujeción a condiciones determinadas; por ejemplo, respecto de la circulación, la residencia y el empleo. Un Estado puede también imponer condiciones generales a un extranjero que se halle en tránsito. No obstante, una vez que se les permite entrar en el territorio de un Estado parte, los extranjeros tienen todos los derechos establecidos en el Pacto. ${ }^{26}$

El derecho a circular libremente por el territorio del Estado y a elegir en él su residencia corresponde a toda persona que se halle legalmente en ese territorio (artículo 12.1). Según el Comité, en principio los nacionales de un Estado siempre se encuentran legalmente dentro del territorio de ese Estado; la legalidad de la presencia de un extranjero, en cambio, es una cuestión regida por el derecho interno, aunque por supuesto éste debe respetar las obligaciones internacionales del Estado. Un extranjero que ha entrado ilegalmente a un Estado, pero cuya condición se ha regularizado, se encuentra legalmente dentro del territorio. ${ }^{27}$

\footnotetext{
${ }^{25}$ Observación General Núm. 27, pfo. 1.

${ }^{26}$ Observación General Núm. 15, pfo. 6.

${ }^{27}$ Observación General Núm. 27, pfo. 4.
} 
Esta revista forma parte del acervo de la Biblioteca Jurídica Virtual del Instituto de Investigaciones Jurídicas de la UNAM

Dado que el derecho interno en cuanto establece el carácter legal o ilegal de la presencia del extranjero debe adecuarse al derecho internacional, el Comité ha revisado las calificaciones hechas por los Estados. Así lo hizo en el caso Celepli c. Suecia. Las autoridades suecas habían ordenado la expulsión de un extranjero, pero habían suspendido la ejecución de la medida por la existencia de un riesgo de persecución en su país de origen. Suecia consideraba que la presencia del extranjero en su territorio era ilegal, aunque se abstuviera de ejecutar la expulsión. El Comité, en cambio, calificó la presencia como legal a efectos del Pacto. ${ }^{28}$

A diferencia del derecho a entrar en un determinado país, el derecho a salir del mismo corresponde a todas las personas, de acuerdo con el artículo 12.2 del Pacto ("toda persona tendrá derecho a salir libremente de cualquier país, incluso del propio"). La libertad de salir del territorio de un Estado no puede hacerse depender de ningún fin concreto o del plazo que el individuo decida permanecer fuera del país; en consecuencia, dicha libertad incluye el viaje temporal al extranjero y la partida en caso de emigración permanente. Igualmente, el derecho de la persona a determinar el Estado de destino está incluido en el ámbito de protección. ${ }^{29}$

El artículo 12.2 impone obligaciones tanto al Estado de residencia como al Estado de la nacionalidad. Como para los viajes internacionales generalmente es necesario contar con documentos adecuados, en particular un pasaporte, el derecho a salir del Estado debe incluir obtener los documentos de viaje necesarios; la emisión del pasaporte corresponde normalmente al Estado de la nacionalidad de la persona. La negativa de un Estado a emitir un pasaporte o a prorrogar su validez a un nacional que reside en el extranjero, puede privar a esa persona del derecho de salir del país de residencia y de viajar a otra parte; no constituye justificación el que un Estado alegue que ese nacional tendría derecho a volver a su territorio sin pasaporte. ${ }^{30}$

Las restricciones a las libertades de circulación, residencia y salida del territorio sólo son posibles cuando "se hallen previstas en la ley, sean necesarias para proteger la seguridad nacional, el orden público, la salud o la moral públicas o los derechos y

\footnotetext{
${ }^{28}$ Celepli v. Sweden, CCPR/C/51/D/456/1991 (1994).

${ }^{29}$ Observación General Núm. 27, pfo. 8.

${ }^{30}$ Ibidem, pfo. 9.
} 
Esta revista forma parte del acervo de la Biblioteca Jurídica Virtual del Instituto de Investigaciones Jurídicas de la UNAM

libertades de terceros, y sean compatibles con los demás derechos reconocidos en el presente Pacto" (artículo 12.3). Las restricciones que se impongan a estos derechos no deben anular el principio de la libertad de circulación. ${ }^{31}$

Las diferencias de trato en materia de circulación y residencia entre nacionales y extranjeros, así como entre distintas categorías de extranjeros, no son ilícitas, siempre que estén justificadas en los criterios del Pacto. ${ }^{32}$ Como tales restricciones, entre otras cosas, deben respetar los derechos reconocidos en el Pacto, los Estados parte, al limitar la libertad de circulación de un extranjero no podrán impedir arbitrariamente que regrese a su propio país. ${ }^{33}$ Además, la aplicación de las restricciones permisibles debe ser compatible con los principios fundamentales de igualdad y no discriminación. ${ }^{34}$

En diversos casos individuales el Comité ha reconocido la legitimidad de las restricciones impuestas a la libertad de circulación de extranjeros. En Celepli c. Suecia dijo que la obligación de permanecer en un pequeño municipio impuesta a una persona sospechosa de actividades terroristas era compatible con el artículo 12.3. ${ }^{35}$ En Karker $c$. Francia se llegó al mismo resultado respecto de otro sospechoso de terrorismo, que en lugar de ser expulsado fue confinado en un departamento del país. ${ }^{36}$

Los extranjeros pueden ampararse también en el principio de igualdad ante la ley del artículo 26 del Pacto. Sin embargo, el Comité ha afirmado que no toda diferencia de trato puede ser considerada contraria a tal principio: algunas distinciones entre nacionales y extranjeros pueden resultar legítimas. Desde luego, esto no quiere decir que toda distinción entre nacionales y extranjeros lo sea. En Adam c. República Checa, por ejemplo, se halló que una distinción de ese tipo resultaba ilegítima. ${ }^{37}$

${ }^{31}$ Ibidem, pfo. 2.

32 Ibidem, pfo. 4; Observación General Núm. 15, pfo. 8.

${ }^{33}$ Observación General Núm. 15, pfo. 8.

${ }^{34}$ Observación General Núm. 27, pfo. 18. Así, las medidas que impiden a las mujeres su libertad de circulación o salir del país sin contar con el consentimiento o la compañía de un varón, constituyen una violación del artículo 12.

${ }^{35}$ Celepli v. Sweden.

${ }^{36}$ Salah Karker v. France, CCPR/C/70/D/833/1998 (2000).

37 Josef Frank Adam v. The Czech Republic, CCPR/C/57/D/586/1994 (1996). 
Esta revista forma parte del acervo de la Biblioteca Jurídica Virtual del Instituto de Investigaciones Jurídicas de la UNAM

Según considera el Comité, los Estados parte deben, en sus informes a aquél, prestar atención a la situación de los extranjeros e informar sobre las circunstancias en que tratan a los extranjeros de manera diferente a sus propios nacionales y cómo justifican la diferencia de trato. ${ }^{38}$ Es importante que los Estados informen de todas las restricciones jurídicas y prácticas que aplican al derecho de salida, tanto a nacionales como a extranjeros; los Estados deben también incluir información sobre las medidas que impongan sanciones a los transportistas internacionales que lleven a dichos Estados personas sin los documentos exigidos, en caso de que esas medidas afecten el derecho de salir de otro país. ${ }^{39}$

\section{LÍMITES SUSTANTIVOS A LA EXPULSIÓN}

Como ya hemos visto, sólo los nacionales tienen (al menos en principio) un derecho a permanecer en el territorio del Estado (artículo 12.4). En efecto, dado que según el artículo mencionado un Estado no puede impedir arbitrariamente el ingreso de su nacional al territorio, parece que tampoco podría expulsar arbitrariamente a sus nacionales. Este derecho implica la prohibición de traslados forzosos de población o de expulsiones en masa a otros países. ${ }^{40}$

El Pacto no contiene ninguna disposición expresa que establezca límites sustantivos a la expulsión de los extranjeros, es decir que defina casos concretos en los que un extranjero no puede ser expulsado. Algunos de estos límites pueden provenir del derecho consuetudinario. Tal es el caso de la ya nombrada regla de non refoulement, originada en el ámbito del derecho de los refugiados, y de la prohibición de discriminación, que también resulta aplicable a las medidas de expulsión. ${ }^{41}$

No obstante, aunque el Pacto no contenga disposiciones expresas sobre los límites sustantivos, éstos pueden surgir implícitamente de otras disposiciones del mismo. En efecto, el Comité ha admitido que en algunos casos un extranjero puede tener un derecho a ingresar a un Estado, o incluso un derecho a ingresar y residir en él. Estos

\footnotetext{
${ }^{38}$ Observación General Núm. 15, pfo. 4.

${ }^{39}$ Observación General Núm. 27, pfo. 10.

40 Ibidem, pfo. 19.

${ }^{41}$ Goodwin-Gill, Guy S., op. cit., p. 532; Kamto, Maurice, Quinto informe sobre la expulsión de extranjeros, A/CN.4/611, 2009, p. 151.
} 
derechos no se derivan, cuando existen, del artículo 12, sino de artículos del Pacto. Por ejemplo, un extranjero podría acogerse a la protección del Pacto respecto del ingreso o la residencia cuando se plantean cuestiones de no discriminación, de prohibición de trato inhumano y de respeto de la vida de la familia. ${ }^{42}$ De hecho, la mayor parte de la jurisprudencia sobre la expulsión de extranjeros trata de los riesgos de violaciones de los derechos del extranjero posteriores a la expulsión o del impacto de la expulsión sobre la vida familiar. ${ }^{43}$

\section{Prohibición de discriminación}

El Estado debe abstenerse de ejercer su derecho a expulsar de modo discriminatorio. ${ }^{44}$ Sin embargo, los criterios de interpretación de este principio han sido en general restrictivos. En el caso Tsarjov c. Estonia, el Comité declaró que no existía violación del principio de igualdad ante la ley (artículo 26) ni del de no discriminación en los derechos del Pacto (artículo 2.1) en la legislación del Estado que prohibía emitir un permiso de residencia a los ex miembros de las fuerzas armadas de un Estado extranjero, ya que esta medida se justificaba en el contexto histórico de las relaciones de Estonia con la Unión Soviética, y por ello se apoyaba en consideraciones de seguridad nacional. ${ }^{45}$

\section{Non refoulement}

Un ámbito que ha recibido mayor atención en relación con los límites sustantivos a la expulsión ha sido el del derecho a la vida y la prohibición de la tortura y otros tratos análogos. El Comité ha advertido que la obligación de respetar y garantizar los derechos del Pacto a todas las personas que estén en su territorio y a todas las que estén bajo su control implica que los Estados parte no pueden extraditar, deportar, expulsar o hacer salir de algún modo de su territorio a una persona "cuando haya razones de peso para creer que existe un riesgo real de daño irreparable, tal como el daño previsto en los artículos 6o. (derecho a la vida) y 7o. (prohibición de la tortura y otros tratos crueles,

\footnotetext{
${ }^{42}$ Observación General Núm. 15, pfo. 5.

${ }^{43}$ O'Donnell, Daniel, Derecho internacional de los derechos humanos: normativa, jurisprudencia y doctrina de los sistemas universal e interamericano, México, Oficina del Alto Comisionado de las Naciones Unidas en México-Tribunal Supremo del Distrito Federal, 2012, p. 629.

${ }^{44}$ En el mismo sentido, Draft Articles on the Expulsion of Aliens, artículo 14.

${ }^{45}$ Sarjov v. Estonia, CCPR/C/91/D/1223/2003 (2007).
} 
Esta revista forma parte del acervo de la Biblioteca Jurídica Virtual del Instituto de Investigaciones Jurídicas de la UNAM www.juridicas.unam.mx

inhumanos o degradantes) del Pacto", ya sea en el país hacia el que se va a efectuar la salida forzada o en cualquier país al que la persona sea expulsada posteriormente. ${ }^{46}$

El Comité declara así que el principio de non refoulement está implícito en el Pacto. En lo que se refiere a la prohibición de tortura y otros tratos análogos del artículo 7o., esta consideración es coherente con el artículo 3o. de la Convención contra la Tortura y otros Tratos o Penas Crueles, Inhumanos o Degradantes, que prohíbe la expulsión en caso de riesgo de tortura y que ha sido respaldado con una larga lista de precedentes del Comité contra la Tortura. ${ }^{47}$

La jurisprudencia del Comité reafirma la idea de que si un Estado expulsa a una persona que se encuentra en su territorio y sujeta a su jurisdicción en circunstancias tales que existe un riesgo de que sus derechos bajo el Pacto sean violados en otra jurisdicción, el propio Estado expulsor podría estar en violación del Pacto. Así, hay violación del artículo 7o. si se expulsa a un extranjero en un contexto de riesgo de sufrir persecución exigiendo seguridades diplomáticas que no son efectivas ${ }^{48}$ o si se expulsa a un disidente político que había pasado seis meses en detención policial y cuya familia recibía presiones en el país de origen ${ }^{49}$. Igualmente, hay violación de los artículos 6.1 y 70.

${ }^{46}$ Observación General Núm. 31: La índole de la obligación jurídica general impuesta, 80 periodo de sesiones, HRI/GEN/1/Rev.7 at 225 (2004), p. 12; Observación General Núm. 20: Artículo 7 Prohibición de la tortura u otros tratos o penas crueles, inhumanos o degradantes, 44 periodo de sesiones, HRI/GEN/1/Rev.7 at 173 (1992), p. 9; Los Draft Articles on the Expulsion of Aliens, reproducen esta idea en los artículos 23 (prohibiendo la expulsión cuando exista riesgo para la vida, aunque sólo si ese riesgo se basa en una base de discriminación prohibida en derecho internacional) y 24 (prohibiendo la expulsión en caso de riesgo de tortura o tratos o penas crueles, inhumanos o degradantes).

${ }^{47}$ Entre otros, Mutombo v. Switzerland, CAT/C/12/D/13/1993 (1994); Kisoki v. Sweden, CAT/C/16/D/41/1996 (1996); Tala v. Sweden, CAT/C/17/D/43/1996 (1996); Paez v. Sweden, CAT/C/18/D/39/1996 (1997); Aemei v. Switzerland, CAT/C/18/D/34/1995 (1997); A.F. v. Sweden, CAT/C/20/D/89/1997 (1997); Ayas v. Sweden, CAT/C/21/D/97/1997 (1998); Korban v. Sweden, CAT/C/21/D/88/1997 (1998); Haydin v. Sweden, CAT/C/21/D/101/1997 (1998); Elmi v. Australia, CAT/C/22/D/120/1998 (1999); A.S. v. Sweden, CAT/C/25/D/149/1999 (1999); Arana v. France, CAT/C/23/D/63/1997 (1999); Ríos v. Canada, CAT/C/33/D/133/1999 (2004); T.A. v. Sweden, CAT/C/34/D/226/2003 (2005); Agiza v. Sweden, CAT/C/34/D/233/2003 (2005); Brada v. France, CAT/C/34/D/195/2002 (2005); Dadar v. Canadá, CAT/C/35/D/258/2004 (2005).

\footnotetext{
${ }^{48}$ Mohammed Alzery v. Sweden, CCPR/C/88/D/1416/2005 (2006). Zhakhongir Maksudov and Adil Rakhimov, Yakub Tashbaev and Rasuldzhon Pirmatov v. Kyrgyzstan, CCPR/C/93/D/1461,1462,1476 \& 1477/2006 (2008).

${ }^{49}$ Hamida v. Canada, CCPR/C/98/D/1544/2007 (2010).
} 
Esta revista forma parte del acervo de la Biblioteca Jurídica Virtual del Instituto de Investigaciones Jurídicas de la UNAM

si se expulsa a Somalia a alguien que nunca ha vivido, carece de familia y de cualquier apoyo de clan allí y que no habla el idioma. ${ }^{50}$ En otros casos ha rechazado la alegación de que la expulsión violaba el artículo 7o. por falta de pruebas suficientes sobre los tratos que recibiría el expulsado. ${ }^{51}$

Algunos casos merecen una atención particular. En M. I. c. Suecia se analizó el riesgo de recibir tratos prohibidos en razón de la orientación sexual. Una mujer nacional de Bangladesh alegaba que había sido casada forzosamente por sus padres cuando éstos se enteraron de que era lesbiana y que había sufrido persecución de parte de las autoridades de su país. El Comité entendió que la implementación de la decisión adoptada por Suecia (que todavía no había sido ejecutada) significaría efectivamente una violación del artículo 7o. del Pacto. ${ }^{52}$ La misma consideración se dio en un caso relativo a una niña que, en caso de ser expulsada, corría riesgo de ser sometida a una mutilación genital por miembros de su familia en el país de origen (Kaba c. Canadá). ${ }^{53}$

En C. c. Australia, el Comité afirmó que existía una obligación de no expulsar en el caso de una persona gravemente enferma y que no podría encontrar, en el país al que era expulsada, tratamiento adecuado para su enfermedad. Sin embargo, esta controversia se daba en circunstancias muy particulares que tornan dudosa la extrapolación del criterio a otros casos. Se trataba de un nacional iraní de religión cristiana, que alegaba temor de persecución por sus convicciones religiosas. El Estado le había privado de su libertad mientras decidía sobre su solicitud de refugio (privación de libertad luego declarada arbitraria por el Comité), y esta privación de libertad le había provocado una grave enfermedad mental. Con posterioridad, y como consecuencia de un delito cometido por el refugiado una vez liberado, el estatuto de refugiado le había sido revocado. Así, la enfermedad mental para la cual no podría encontrar remedio en su propio país era una consecuencia de un ilícito cometido por el propio Estado. A esto se sumaba el riesgo de persecución en su país por motivos religiosos. ${ }^{54}$ En un caso posterior,

\footnotetext{
50 Jama Warsame v. Canada, CCPR/C/102/D/1959/2010 (2011).

51 Torres v. Finland, CCPR/C/38/D/291/1988 (1990). G.T. v. Australia, CCPR/C/61/D/706/1996 (1997).

${ }^{52}$ M. I. v. Suecia, CCPR/C/108/D/2149/2012 (2013).

${ }^{53}$ Kaba v. Canada, CCPR/C/98/D/1465/2006 (2010).

${ }^{54}$ C. v. Australia, CCPR/C/76/D/900/1999 (2002).
} 
Esta revista forma parte del acervo de la Biblioteca Jurídica Virtual del Instituto de Investigaciones Jurídicas de la UNAM

el Comité evitó dar más precisiones sobre este tipo de situaciones, al considerar que el agravio no había sido suficientemente sustanciado. ${ }^{55}$

En el caso Esposito c. Finlandia, el Comité no halló violación a los artículos 7o. y 10 por el hecho de que se extraditara a una persona sin solicitar garantías de que no sería aplicada una cadena perpetua. Sin embargo, parecía dejarse abierta la posibilidad de que se considerara la condena a una cadena efectivamente perpetua como contraria al artículo 7o., ya que lo que afirmó es que en el caso concreto no era necesario y previsible que se aplicara tal condena. ${ }^{56}$

El Comité ha sido oscilante en cuanto al rigor del nexo que ha de existir entre la expulsión y el daño irreparable que la torna ilícita. En algunos casos ha afirmado que es necesario que la violación de los derechos sea una consecuencia necesaria y previsible del acto de expulsión. ${ }^{57}$ En otros, en cambio, se ha contentado con que existan bases sustanciales para creer que hay un riesgo rea/ de daño irreparable. ${ }^{58}$

La violación del Pacto debe evaluarse de acuerdo con la información de la que el Estado disponía, o debía disponer, al momento de la deportación. No es necesario que la tortura o la muerte se hayan producido efectivamente después de la deportación, aunque el conocimiento de la situación subsiguiente a la deportación puede ser útil a efectos de determinar si existía un riesgo inicial. ${ }^{59}$ Igualmente, hay que tener en cuenta que, según los precedentes reseñados, el riesgo de persecución puede tener causa no sólo en la actuación de las autoridades públicas, sino también de particulares. El Comité sigue en este punto los precedentes de otras instancias internacionales que declaran que también existe la obligación internacional de no expulsar cuando la persona esté sujeta a

\footnotetext{
${ }^{55}$ S. Y. L. v. Australia, CCPR/108/D/1897/2009 (2013).

${ }^{56}$ Mario Esposito v. Spain, CCPR/C/89/D/1359/2005 (2007).

${ }^{57}$ Hamida v. Canada. G.T. v. Australia. Mario Esposito v. Spain.

${ }^{58}$ Jama Warsame v. Canada. Kaba v. Canada.

${ }^{59}$ Zhakhongir Maksudov and Adil Rakhimov, Yakub Tashbaev and Rasuldzhon Pirmatov v. Kyrgyzstan, CCPR/C/93/D/1461,1462,1476 \& 1477/2006 (2008).
} 
Esta revista forma parte del acervo de la Biblioteca Jurídica Virtual del Instituto de Investigaciones Jurídicas de la UNAM

riesgos provenientes de particulares a los que las autoridades son incapaces de controlar. ${ }^{60}$

También puede haber violación del Pacto si se extradita a alguien que puede ser condenado a pena de muerte, cuando la aplicación de esta pena resulta ilícita. En Kindler c. Canadá, el Comité estudió la situación de un nacional estadounidense, condenado a muerte en su país, y cuya extradición se había solicitado a Canadá. Aunque el tratado de extradición entre ambos Estados permitía a Canadá, que había abolido la pena de muerte, solicitar garantías de que tal pena no sería aplicada o ejecutada, Canadá no solicitó tales garantías. El Comité señaló con acierto que lo que estaba en juego en el caso no era si una vez extraditado a los Estados Unidos, el interesado sufriría violaciones a sus derechos a la luz del Pacto. El Comité no podía entrar en estas consideraciones puesto que Estados Unidos no era parte en el Primer Protocolo adicional del que surgía su competencia para examinar comunicaciones individuales. Lo que el Comité debía examinar era si Canadá, que sí era parte en el Primer Protocolo, por el hecho mismo de la extradición violaba sus obligaciones a la luz del Pacto. En el caso, el Comité sostuvo que si Canadá hubiera abolido la pena de muerte (salvo para algunos delitos militares) no lo obligaba a rechazar el pedido de extradición o a pedir garantías a Estados Unidos. Canadá no era parte en el Segundo Protocolo, que prohíbe en términos absolutos la pena de muerte, sino sólo en el Pacto, cuyo artículo 6o. limita, pero no prohíbe totalmente, tal pena. Dado que en la condena por los tribunales estadounidenses se habían respetado las garantías del artículo 6.2 (se trataba de un crimen grave, la pena había sido adoptada de conformidad con la ley, etcétera), Canadá no estaba obligado, según las reglas de Pacto, a negarse a extraditar o a solicitar garantías. Sólo habría habido violación de parte de Canadá si la decisión de extraditar hubiera sido tomada de modo arbitrario o sumario, lo que no había sucedido. En el caso Kindler, el Comité descartó además que existiera violación del artículo 7o., en cuanto prohíbe la tortura y otros tratos o penas crueles, inhumanos o degradantes. ${ }^{61}$

En otro caso de extradición a Estados Unidos, esta vez de un nacional británico fugado a Canadá, se llegó a las mismas conclusiones respecto de la ausencia de violación del

\footnotetext{
${ }^{60}$ Tribunal Europeo de Derechos Humanos, H. L. R. v. Francia, sentencia del 27 de abril de 1997, demanda $24573 / 94$.

${ }^{61}$ Kindler v. Canadá, CCPR/C/48/D/470/1991 (1993), pfo. 13.2.
} 
Esta revista forma parte del acervo de la Biblioteca Jurídica Virtual del Instituto de Investigaciones Jurídicas de la UNAM

artículo 6. Sin embargo, el Comité constató que dado que la muerte se ejecutaría mediante asfixia con gas, la extradición sería violatoria del artículo 7o. del Pacto. ${ }^{62}$

Con posterioridad, el Comité cambió el criterio que había adoptado en Kindler. En el caso Judge c. Canadá, el Comité declaró que un Estado que ha eliminado la pena de muerte no puede extraditar una persona a un país donde ha sido condenado a la pena capital, y esto incluso si la aplicación de la pena de muerte en el país requirente fuera compatible con los requisitos de los artículos 6.2, 7o. y 14 del Pacto. ${ }^{63}$ El criterio de Kindler sigue siendo todavía válido para el caso de extradición entre dos países que no han abolido la pena de muerte.

En aquellos casos donde no pueda constatarse una violación del artículo 6o. en sí mismo (porque la extradición se hace entre dos países que no han abolido la pena de muerte y los requisitos del artículo para la licitud de la pena están cumplidos) sigue siendo posible constatar una violación del artículo 7o. por el modo en que la pena es aplicada. En este caso, dice el Comité cambiando ligeramente la fundamentación jurídica utilizada en casos anteriores, la pena de muerte impuesta en violación al artículo 7o. implicaría también una violación del artículo 6.2 del Pacto. ${ }^{64}$

Al igual que en el caso de riesgo de tortura, es necesario definir el criterio sobre el nexo que debe haber entre el acto de expulsión y la aplicación de la pena de muerte. En un caso de extradición desde Australia (que es parte en el Segundo Protocolo y ha abolido por consiguiente la pena de muerte) hacia Malasia, el Comité descartó la existencia de una violación del artículo 6o. y del Segundo Protocolo porque consideró que no había prueba de que la aplicación de la pena de muerte fuera una consecuencia necesaria y previsible de la deportación. ${ }^{65}$ Evidentemente, este criterio resulta

\footnotetext{
${ }^{62}$ Chitat Ng v. Canadá, CCPR/C/49/D/469/1991 (1994).

${ }^{63}$ Roger Judge v. Canadá, CCPR/C/78/D/829/1998 (2003). Dado que el Comité se refiere a aquellos países que han abolido la pena de muerte, se ha de entender que los efectos son semejantes tanto si el país es parte en el Segundo Protocolo (y ha abolido la pena de muerte por imperativo de éste) como si el país ha abolido simplemente la pena de muerte sin ser parte en el Protocolo.

${ }^{64}$ Zhakhongir Maksudov and Adil Rakhimov, Yakub Tashbaev and Rasuldzhon Pirmatov v. Kyrgyzstan. Comparar con el caso Chitat Ng. v. Canadá, arriba citado, donde el Comité no concluyó que la pena de muerte aplicada en violación del artículo 7o. conllevara además una violación del artículo 6.2.

${ }^{65}$ G.T. v. Australia.
} 
Esta revista forma parte del acervo de la Biblioteca Jurídica Virtual del Instituto de Investigaciones Jurídicas de la UNAM

demasiado estricto, ya que exige prácticamente la seguridad de que la pena de muerte será aplicada. En otros casos el Comité se contentó con una prueba menor. Así, dijo que sería suficiente que hubiera bases sustanciales para considerar que el Estado estaba exponiendo al expulsado a un riesgo real de daño irreparable. El Comité halló entonces una violación de los artículos 6.1 (Australia había abolido la pena de muerte, y por lo tanto no podía expulsar hacia un país donde existía el riesgo de ser ejecutado) y 70. (porque el modo del juicio que se podía esperar hacía que la imposición de la pena de muerte fuera un trato de los prohibidos por ese artículo). ${ }^{66}$

En teoría también resultaría posible que la expulsión fuera ilícita si existiera un riesgo de violación de otros derechos del Pacto, siempre que revistiera suficiente gravedad. Respecto del artículo 9o. (derechos procesales), por ejemplo, aunque el Comité consideró que tal riesgo no existía en el concreto caso analizado, no descartó en abstracto la posibilidad de ilicitud de la expulsión si ésta tuviera como consecuencia someter al expulsado a un juicio injusto. ${ }^{67}$

\section{La protección de la vida familiar}

De acuerdo con lo previsto en el Pacto, una expulsión será ilícita en la medida en que implique una injerencia arbitraria en la vida familiar, prohibida por el artículo 17. Dos elementos resultan pues de relevancia: que haya una injerencia y que la misma no pueda ser justificada. Igualmente, la expulsión puede resultar ilícita si viola los derechos de la infancia, protegidos por el artículo 23. Son las circunstancias del caso las que han de permitir determinar si existe injerencia injustificada y si se vulneran los derechos de la infancia.

Por ejemplo, en el caso Winata c. Australia el Comité admitió la existencia de una injerencia arbitraria en la vida familiar (artículo 17) así como la violación de los derechos del niño (artículo 23). Australia intentaba deportar a los padres de un joven de 13 años, nacido en Australia, y de nacionalidad australiana, en razón únicamente de su situación migratoria irregular. Aunque el Comité admitió que el solo hecho de que un niño tuviera la nacionalidad de un país no era suficiente para establecer automáticamente que la expulsión de sus padres fuera ilícita, también sostuvo que la facultad de expulsión no era

\footnotetext{
${ }^{66}$ Kwok Yin Fong v. Australia, CCPR/C/97/D/1442/2005 (2009).

${ }^{67}$ G.T. v. Australia.
} 
Esta revista forma parte del acervo de la Biblioteca Jurídica Virtual del Instituto de Investigaciones Jurídicas de la UNAM

ilimitada. En el presente caso, teniendo en cuenta las circunstancias del niño y el hecho de que los padres llevaban catorce años viviendo en Australia, para que la expulsión no fuera violatoria del Pacto el Estado debería haber demostrado que existían razones de peso, más allá de la simple aplicación de las leyes de inmigración, que justificaran la expulsión. ${ }^{68}$

Hay que tener en cuenta, sin embargo, que el solo hecho de que los hijos menores tengan la nacionalidad del Estado no es suficiente para evitar la expulsión de sus padres extranjeros. En Vital María Fernandes y otros c. Países Bajos el Comité sostuvo que la supuesta afectación de la vida familiar por expulsión del extranjero padre de tres hijos menores con nacionalidad holandesa no había sido suficientemente sustanciada, y rechazó la denuncia. ${ }^{69}$

En el caso Aumeeruddy-Cziffra c. Mauricio, el Comité sostuvo que dado que la residencia común de marido y mujer es la situación normal de una familia, la exclusión de uno de los cónyuges del país del otro es una injerencia en la vida familiar en los términos del artículo 17 del Pacto. ${ }^{70}$ Sin embargo, el Comité no entró a analizar si esta interferencia era efectivamente arbitraria. De acuerdo con lo previsto en la legislación de Mauricio, las esposas de los nacionales podían acceder automáticamente a un permiso de residencia, mientras que los esposos de las nacionales (como era el caso) estaban sometidos a un permiso discrecional y precario. El Comité halló que en el caso había una discriminación en razón del sexo, en violación de los artículos 20. (obligación de garantizar derechos), 3o. (igualdad entre hombres y mujeres) y 26 (igualdad ante la ley) en relación con el artículo 17 del Pacto. La legislación mauritana resultaba discriminatoria contra las mujeres que, a diferencia de los hombres de ese país, no podían disfrutar de una vida familiar normal. También se constató una violación de la prohibición de discriminación de los artículos 20., 30. y 26 en relación con los derechos del niño (artículo 23), respecto de los hijos de estas parejas.

En Bakhtiyari y Bakhtiyari c. Australia se declaró que la expulsión de la esposa y los hijos, separándolos del esposo que tenía un visado de protección que le permitía residir

\footnotetext{
${ }^{68}$ Hendrick Winata and So Lan Li v. Australia, CCPR/C/72/D/930/2000 (2001).

${ }^{69}$ Vital María Fernandes et al. v. Netherlands, CCPR/C/93/D/1513/2006 (2008).

${ }^{70}$ Shirin Aumeeruddy-Cziffra and 19 other Mauritian women v. Mauritius, Supp. Núm. 40 (A/36/40) at 134 (1981).
} 
Esta revista forma parte del acervo de la Biblioteca Jurídica Virtual del Instituto de Investigaciones Jurídicas de la UNAM

en el país, aun cuando existían procedimientos legales para retirar el visado por un supuesto fraude cometido en su obtención, violaba los artículos 17 y 23 del Pacto, teniendo en cuenta las circunstancias del caso. ${ }^{71}$

La existencia de antecedentes penales que puedan justificar la expulsión no alcanza, por sí sola, a justificar una injerencia en la vida familiar. En Madafferi c. Australia (caso de un italiano que iba a ser expulsado a su país por la existencia de antecedentes penales que había ocultado a las autoridades australianas), se halló igualmente una violación de los artículos 17, 23 y 24, ya que la expulsión rompería la vida familiar. ${ }^{72} \mathrm{Y}$ en el caso Jama Warsame c. Canadá se concluyó que a pesar de las repetidas condenas penales de la persona sujeta a expulsión, el hecho de que tuviera toda su familia en Canadá junto con la dificultad de comunicación que se seguiría si fuera expulsado a Somalia, así como la dificultad de su familia para viajar y de él para regresar a Canadá hacían que la expulsión implicara una injerencia arbitraria en la vida familiar y fuera, por ello, contraria a los artículos 17 y 23 del Pacto. ${ }^{73}$ En Byahuranga c. Dinamarca, en cambio, se halló que una condena por tráfico de drogas sobre la base de la cual se ordenó la expulsión es una razón suficiente para que la interferencia con la vida familiar del expulsado resultara justificada. $^{74}$

En otros casos el Comité ha sostenido que no había una injerencia arbitraria en la vida familiar en los términos del artículo 17. En Canepa c. Canadá, negó que hubiera tal injerencia respecto de una persona de nacionalidad italiana, soltera y sin hijos, expulsada en razón de sus antecedentes penales, y respecto de la cual la expulsión no significaba una ruptura total de contactos con sus padres y hermanos. ${ }^{75}$ En Stewart $c$. Canadá se llegó a la misma conclusión, a pesar de que el autor de la denuncia tenía dos hijas que vivían en Canadá. ${ }^{76}$ Igualmente, el Comité ha afirmado que no hay interferencia

\footnotetext{
${ }^{71}$ Ali Aqsar Bakhtiyari and Roqaiha Bakhtiyari v. Australia, CCPR/C/79/D/1069/2002 (2003).

${ }^{72}$ Francesco Madafferi v. Australia, CCPR/C/81/D/1011/2001 (2004).

73 Jama Warsame v. Canada.

${ }^{74}$ Jonny Rubin Byahuranga v. Denmark, CCPR/C/82/D/1222/2003 (2004).

75 Giosue Canepa v. Canadá, CCPR/C/59/D/558/1993 (1997).

${ }^{76}$ Charles E. Stewart v. Canadá, CCPR/C/58/D/538/1993 (1996).
} 
Esta revista forma parte del acervo de la Biblioteca Jurídica Virtual del Instituto de Investigaciones Jurídicas de la UNAM

con la vida familiar si la familia puede volver a reunirse en el país de destino del expulsado o en un tercer país (Nakrash y Qifen c. Suecia). ${ }^{77}$

De estos casos, el Comité aplica un test de equilibrio entre la vida familiar, por un lado, y el interés del Estado en expulsar al extranjero, por otro. Así, cuanto más fuertes sean los lazos familiares más potentes habrán de ser las razones del Estado para justificar la expulsión. Razones de expulsión débiles (por ejemplo, la mera irregularidad migratoria) frente a lazos familiares fuertes (por ejemplo, hijos residentes en o nacionales del Estado que expulsa) hacen que la expulsión sea una injerencia arbitraria en la vida familiar. ${ }^{78}$

La oposición a la expulsión puede provenir de una combinación de los argumentos de no discriminación, non refoulement y violación de la vida familiar. En un caso que el Comité analizó en este sentido declaró algunas pretensiones inadmisibles (por falta de sustanciación) y rechazó otras por motivos fácticos, aunque por supuesto dejó subsistente la posibilidad teórica de combinación de argumentos. ${ }^{79}$

\section{El derecho a permanecer en el propio país}

Otros límites sustantivos a la expulsión pueden provenir de la particular redacción del artículo 12.4, que establece que nadie puede ser privado del derecho a entrar en su propio país. En principio, esta última expresión hace referencia al país de la nacionalidad. ${ }^{80}$ Sin embargo, en la Observación general núm. 27, el Comité hizo una interpretación un poco más amplia. La protección del artículo comprendería no sólo a un nacional, sino también a aquella persona que “debido a vínculos especiales o a pretensiones en relación con un país determinado, no puede ser considerada como un simple extranjero". Por ejemplo: los nacionales de un país que hubieran sido privados en él de su nacionalidad en violación del derecho internacional o las personas cuyo país se haya incorporado o transferido a otra entidad nacional cuya nacionalidad se les deniega. El artículo también abarcaría algunas categorías de residentes a largo plazo, en particular,

\footnotetext{
${ }^{77}$ Mahmoud Walid Nakrash and Liu Qifen v. Sweden, CCPR/C/94/D/1540/2007 (2008).

${ }^{78}$ En el mismo sentido, Draft Articles on the Expulsion of Aliens, artículo 18.

${ }^{79}$ Fan Biao Lin v. Australia, CCPR/C/107/D/1957/2010 (2013).

${ }^{80}$ Observación General Núm. 15, pfo. 5.
} 
pero no exclusivamente, los apátridas privados arbitrariamente del derecho a adquirir la nacionalidad del país de residencia. ${ }^{81}$

La interpretación de esta expresión en los casos abordados por el Comité, sin embargo, ha sido generalmente restrictiva. En Stewart c. Canadá el Comité negó que Canadá pudiera considerarse su propio país respecto de un nacional británico, que había vivido de los siete a los 30 años en este Estado y que decía ignorar que sus padres nunca habían solicitado para él la nacionalidad canadiense. De este modo, avaló la decisión canadiense de expulsar a esta persona por sus antecedentes penales. El Comité hizo hincapié en que, a pesar de que la legislación canadiense era generosa respecto de la naturalización, el interesado nunca la había solicitado. ${ }^{82}$ En Madafferi c. Australia se sostuvo que no había violación del artículo 12, ya que Australia no podía considerarse su país respecto de Madafferi, aunque llevara muchos años viviendo y tuviera ahí su familia. ${ }^{83}$

En Jama Warsame c. Canadá, en cambio, el Comité consideró que una persona que había vivido casi toda su vida en Canadá, había realizado toda su educación, hablaba el idioma, tenía a su familia nuclear allí y carecía de un vínculo nacional probado con otro Estado, podría considerar a Canadá como su propio país. La deportación a Somalia tornaría prácticamente imposible su reingreso a Canadá, en razón de las regulaciones migratorias de este último. Por ello, y afirmando que hay pocas o ninguna razón que permitiría prohibir a una persona que reingresara a su propio país, el Comité juzgó que la expulsión basada en la existencia de antecedentes penales era arbitraria. ${ }^{84}$

\section{REGLAS FORMALES SOBRE LA EXPULSIÓN}

En el apartado anterior nos hemos dedicado a estudiar las bases sustantivas que pueden generar un derecho del extranjero a permanecer en un Estado, y por ende actuar como obstáculos a su expulsión. Aquí nos ocuparemos, en cambio, de los requisitos formales establecidos por el Pacto para que la expulsión pueda considerarse internacionalmente lícita.

\footnotetext{
${ }^{81}$ Observación General Núm. 27, pfos. 19 y 20.

${ }^{82}$ Charles E. Stewart v. Canadá.

${ }^{83}$ Francesco Madafferi v. Australia.

${ }^{84}$ Jama Warsame v. Canada.
} 
Esta revista forma parte del acervo de la Biblioteca Jurídica Virtual del Instituto de Investigaciones Jurídicas de la UNAM

\section{La prohibición de las expulsiones colectivas}

Una primera exigencia para la legalidad de la expulsión es la relativa a la consideración individual de la situación de cada expulsado. ${ }^{85}$ La prohibición de expulsiones colectivas aparece consagrada en diversos tratados internacionales de derechos humanos. ${ }^{86}$

A diferencia de otros instrumentos internacionales, el Pacto no contiene una norma expresa que prohíba las expulsiones colectivas. Sin embargo, esta exigencia está implícita en el artículo 13, que otorga a cada extranjero el derecho a que se adopte una decisión en su propio caso, lo que no sucede respecto de leyes o decisiones que dispongan expulsiones colectivas o en masa. ${ }^{87}$ En efecto, sólo la disposición que tenga en cuenta las circunstancias individuales del expulsado permite aducir argumentos contra la expulsión y puede ser sometida a revisión ante la autoridad competente o bien ante la persona o personas designadas por ella, exigencia establecida en el artículo 13 que nosotros estudiamos a continuación.

\section{Requisitos formales de la expulsión individual}

La expulsión de extranjeros puede llevarse a cabo siempre que se cumplan determinados requisitos de forma. Según dispone el artículo 13,

...el extranjero que se halle legalmente en el territorio de un Estado Parte en el presente Pacto sólo podrá ser expulsado de él en cumplimiento de una decisión adoptada conforme a la ley; $y$, a menos que razones imperiosas de seguridad nacional se opongan a ello, se permitirá a tal extranjero exponer las razones que lo asistan en contra de su expulsión, así como someter su caso a revisión ante la autoridad competente o bien ante la persona o personas designadas especialmente por dicha autoridad competente, $y$ hacerse representar con tal fin ante ellas.

\footnotetext{
${ }^{85}$ Sobre el tema véase Henckaerts, Jean-Marie, Mass expulsion in modern International law and practice, La Haya, Martinus Nijhoff Publishers, 1995; Chueca Sancho, Ángel, "El derecho internacional prohíbe las expulsiones colectivas de extranjeros", Revista de Derecho Migratorio y Extranjería, núm. 1, 2002, pp. 9-36.

${ }^{86}$ Convención Americana sobre Derechos Humanos, artículo 22.9. Convenio Europeo de Derechos Humanos, artículo 4o. del Protocolo 4. Convención Internacional sobre la Protección de los Derechos de todos los Trabajadores Migratorios y de sus Familiares, artículo 22.1.

${ }^{87}$ Observación General Núm. 15, pfo. 10. En el mismo sentido, Draft Articles on the Expulsion of Aliens, artículo 9o.
} 
Esta revista forma parte del acervo de la Biblioteca Jurídica Virtual del Instituto de Investigaciones Jurídicas de la UNAM

Como surge de la redacción del artículo 13, las garantías en caso de expulsión sólo corresponden a los extranjeros que se hallen legalmente en el territorio del Estado. Esto significa que para determinar el alcance de la protección debe tenerse en cuenta el derecho nacional relativo a las exigencias en materia de entrada y estancia. Particularmente, quienes hayan entrado ilícitamente y los extranjeros que hayan permanecido más tiempo que el permitido por la ley o indicado en el permiso que se les haya extendido no están protegidos por sus disposiciones.

La normativa del Pacto refleja una perspectiva limitada sobre las garantías en caso de expulsión. El Proyecto de Artículos sobre Expulsión de Extranjeros establece en cambio que cualquier expulsión debe estar basada en la ley y respetar determinadas garantías. ${ }^{88}$ Ahora bien, incluso bajo el Pacto, si la cuestión controvertida es la propia licitud de la entrada o permanencia del extranjero, toda decisión a este respecto que desemboque en su expulsión debe adoptarse con arreglo a lo previsto en el artículo señalado. ${ }^{89}$

Por otra parte, las garantías son aplicables a cualquier procedimiento que tenga por objeto la salida obligatoria de un extranjero, se describa ésta en el derecho nacional como expulsión o de otra forma. ${ }^{90}$ En otras palabras, se utiliza el concepto de expulsión en su sentido amplio. De este modo queda también incluida la extradición. En Giry c. República Dominicana ${ }^{91}$ y Cañón García c. Ecuador ${ }^{92}$ se constató, en efecto, la violación del artículo 13 en el caso de la entrega de una persona a las autoridades de un tercer país sin audiencia del extraditado ni decisión formal a su respecto.

En síntesis, dos requisitos para la licitud de la expulsión surgen del artículo 13: el respeto al principio de legalidad y el cumplimiento de ciertas garantías procesales. En lo que hace al principio de legalidad, resulta de interés mencionar el caso Ahmadou Sadio Diallo, en el que la Corte Internacional de Justicia resolvió una demanda presentada por

\footnotetext{
${ }^{88}$ Draft Articles on the Expulsion of Aliens, artículos 40., 50., 26 y 28. Sin embargo, el apartado 4 del artículo 26 establece una excepción para el caso de los extranjeros que se encuentren irregularmente en el territorio del Estado por breve tiempo, y el artículo 27 limita el carácter suspensivo del recurso contra la decisión de expulsión al caso de extranjeros en situación irregular.

${ }^{89}$ Observación General Núm. 15, pfo. 9.

${ }^{90}$ Idem.

${ }^{91}$ Pierre Giry v. Dominican Republic, CCPR/C/39/D/193/1985 (1990).

92 Cañón García v. Ecuador, CCPR/C/43/D/319/1988 at 90 (1991).
} 
Esta revista forma parte del acervo de la Biblioteca Jurídica Virtual del Instituto de Investigaciones Jurídicas de la UNAM www.juridicas.unam.mx

Guinea contra la República Democrática del Congo. ${ }^{93}$ La demanda versaba sobre la situación de un nacional guineano, Ahmadou Sadio Diallo, establecido en el Congo y propietario en este país de dos sociedades mercantiles. A fines de los años ochenta las sociedades de Diallo intentaron el cobro de diversas deudas, entre ellas algunas contra el Estado congoleño. En esa época, el señor Diallo fue encarcelado y luego liberado. En 1995 se ordenó la expulsión de Diallo, quien fue encarcelado por segunda vez, puesto en libertad, nuevamente encarcelado y finalmente expulsado del territorio. ${ }^{94}$

La Corte halló una violación al artículo 13 del Pacto, semejante en su redacción al artículo 12.4 de la Carta Africana, también mencionado, en lo relativo al modo en que se llevó adelante la expulsión. La Corte sostuvo que no se habían respetado las normas internas congoleñas relativas a la expulsión. Sostuvo además que si bien la conformidad con la ley es una condición necesaria del respeto de las normas precitadas, ella no es una condición suficiente, ya que "es necesario que la ley nacional aplicable sea ella misma compatible con las exigencias del Pacto y de la Carta Africana"; por otro lado, “una expulsión no puede ser de carácter arbitrario, ya que la protección contra la arbitrariedad está en el corazón de los derechos garantizados por las normas internacionales de protección de los derechos humanos". ${ }^{95}$

Del texto literal del artículo 13 del Pacto parece seguirse que sería suficiente que la expulsión estuviera fundada en derecho interno, aunque careciera totalmente de motivación sustantiva. De este modo, si el derecho interno permitiera la expulsión puramente discrecional no habría violación del principio de legalidad. Sin embargo, parece estar bien establecido en derecho internacional el deber del Estado de indicar los

${ }^{93}$ Corte Internacional de Justicia, Affaire Ahmadou Sadio Diallo (République de Guinée v. République Démocratique du Congo), sentencia del 30 de noviembre de 2010.

${ }^{94}$ La Corte abordó el caso en dos aspectos: los derechos de Diallo en tanto que individuo y los derechos de Diallo en tanto que socio y gerente de las sociedades comerciales. La Corte declaró inadmisible la demanda en lo relativo a los derechos de las sociedades en sí mismas. El aspecto que aquí nos interesa es evidentemente el primero. Respecto del segundo, sólo diremos, a modo general, que la Corte rechazó todas las pretensiones de Guinea en defensa de los derechos de Diallo como socio y gerente de las sociedades comerciales. En lo relativo a la primera privación de libertad de Diallo, la Corte sostuvo que no estaba en condiciones de resolver ya que la pretensión de Guinea relativa a la privación de derechos de su nacional en razón de la misma había sido tardíamente introducida al proceso y era por lo tanto inadmisible.

${ }^{95}$ Affaire Ahmadou Sadio Diallo (République de Guinée v. République Démocratique du Congo), párrafo 65. 
Esta revista forma parte del acervo de la Biblioteca Jurídica Virtual del Instituto de Investigaciones Jurídicas de la UNAM

motivos de la expulsión. ${ }^{96}$ La lectura sistemática de este deber de motivar la expulsión con el principio de legalidad contenido en el Pacto lleva a la conclusión de que los motivos admisibles de expulsión han de estar previamente establecidos en la ley.

De un modo sustancialmente coincidente, el Comité ha mantenido que aunque el artículo 13 regula directamente sólo el procedimiento y no los fundamentos sustantivos de la expulsión (distinción que, sin embargo, no es siempre clara), ${ }^{97}$ al permitir solamente las expulsiones "en cumplimiento de una decisión adoptada conforme a la ley", su objetivo es impedir las expulsiones arbitrarias. ${ }^{98}$ En el caso Maroufidou c. Suecia, el Comité afirmó que la exigencia de legalidad en la medida de expulsión lleva implícita la idea de que la ley en la cual tal medida se basa ha de ser compatible con las disposiciones del Pacto. ${ }^{99}$

Un problema que suscita el principio de legalidad es que, al hacer depender la licitud de la medida de expulsión en el derecho internacional de su licitud en derecho interno, obliga al órgano internacional a analizar si el Estado aplicó correctamente su propio derecho, actividad que cae normalmente fuera de la competencia de un órgano internacional. Una solución satisfactoria podría ser la de limitar la competencia para declarar la ilicitud de la medida en derecho interno a aquellos casos en los que la aplicación de tal derecho sea manifiestamente arbitraria o de mala fe. Tal parece que es la opción del Comité, que ha afirmado que aunque carece de competencia para evaluar si los Estados han interpretado correctamente su normativa interna, sí puede analizar si han hecho una interpretación de buena fe. ${ }^{100}$

En algunos casos el Comité ha evaluado el respeto a las garantías procesales establecidas por el artículo 13. En Hammel c. Madagascar, se consideró que era una

\footnotetext{
${ }^{96}$ Règles internationales sur l'admission et l'expulsion des étrangers, adoptadas el 9 de septiembre de 1892 en la sesión de Ginebra del Instituto de Derecho Internacional, artículo 30. Draft Articles on the Expulsion of Aliens, artículo 5o. (reconociendo que el artículo es de codificación y no de desarrollo progresivo del derecho internacional).

${ }^{97}$ Office of the High Commissioner for Human Rights, Expulsions of aliens in international human rights lawDiscussion paper, Ginebra, OHCHR, 2006, p. 11.

98 Observación General Núm. 15, pfo. 10.

${ }^{99}$ Anna Maroufidou v. Sweden, CCPR/C/OP/1 at 80 (1985).

${ }^{100}$ Anna Maroufidou v. Sweden.
} 
violación del artículo la expulsión del extranjero sin entrega de una copia de la orden correspondiente, lo que le impedía pedir una revisión de esa orden. ${ }^{101}$ En Karker $c$. Francia, se entendió que la ausencia del interesado en la audiencia en primera instancia no había sido violatoria del artículo 13, ya que había estado representado por su abogado. ${ }^{102}$ En Ahani c. Canada se halló una violación del artículo 13 en relación con el artículo 7o. (que prohíbe los malos tratos) en la decisión de Canadá que impidió presentar alegaciones contra la orden de expulsión por considerar que la misma no exponía al interesado a los tratos prohibidos por el segundo artículo. ${ }^{103}$

No hay hasta la fecha algún caso en que el Comité haya aplicado la excepción de las razones imperiosas de seguridad nacional, que permite no hacer efectivas las garantías relativas a la expulsión. ${ }^{104}$ En el ya nombrado caso Diallo, la Corte Internacional de Justicia halló una violación del derecho, reconocido por el artículo 13 del Pacto, a hacer valer las razones que existan contra la expulsión y a hacer revisar el caso por la autoridad competente. El Estado demandado alegaba que existían razones imperiosas de seguridad nacional que justificaban que estos requisitos no fueran aplicables. Sin embargo, la Corte rechazó este argumento por considerar que el Congo no había presentado ningún elemento de prueba de la existencia de tales razones. Dijo la Corte que aunque corresponde, en principio, a las autoridades nacionales apreciar los motivos que pueden justificar la adopción de tal o cual medida de policía, cuando se trata de hacer excepción a una importante garantía procedimental prevista por un tratado internacional, no se puede estar simplemente al margen de apreciación del Estado, sino que "corresponde al Estado demostrar que las razones imperiosas exigidas por el Pacto existían, o al menos que era posible concluir razonablemente que existían teniendo en cuenta las circunstancias que rodeaban la medida de expulsión". ${ }^{105}$

El Comité de Derechos Humanos ha dicho también que se debe dar a los extranjeros plenas facilidades para entablar recursos en contra de la expulsión. Esto es

\footnotetext{
101 Eric Hammel v. Madagascar, CCPR/C/OP/2 at 179 (1990).

102 Salah Karker v. France.

103 Mansour Ahani v. Canadá, CCPR/C/80/D/1051/2002 (2004).

104 O’Donnell, Daniel, op. cit., p. 630.

${ }^{105}$ Affaire Ahmadou Sadio Diallo (République de Guinée v. République Démocratique du Congo), pfo. 74.
} 
Esta revista forma parte del acervo de la Biblioteca Jurídica Virtual del Instituto de Investigaciones Jurídicas de la UNAM

particularmente importante cuando hay riesgo de violación de los artículos 6o. y 7o. en razón de la expulsión (Maksudov y Rakhimov, Tashbaev y Pirmatov C. Kyrgyzstan). ${ }^{106}$ Además, en la aplicación del artículo 13 no se debe discriminar entre las diferentes categorías de extranjeros. ${ }^{107}$

En los procedimientos de expulsión resultan aplicables otras garantías del Pacto: por ejemplo, si la expulsión implica detención pueden ser aplicables las salvaguardas del Pacto relativas a la privación de la libertad de los artículos 9o. y 10 (que veremos a continuación). ${ }^{108}$ Además, las garantías del artículo 13 deben interpretarse a la luz de las garantías procesales generales reconocidas en el artículo 14.1 del Pacto, que establece la igualdad ante los tribunales de justicia y los principios de imparcialidad, equidad e igualdad de medios procesales. ${ }^{109}$ Así, la expulsión del extranjero mientras rige una orden provisional de no expulsión supone una violación de la igualdad ante los tribunales considerada conjuntamente con el derecho a un remedio efectivo (artículo 2.3). ${ }^{110}$ Si la expulsión se adopta como parte de una sanción penal, o si el derecho penal declara punibles las violaciones de los mandamientos de expulsión, se aplican también las garantías relativas al proceso penal que aparecen en los restantes incisos del mismo artículo. $^{111}$

Según señala el Comité de Derechos Humanos, se debe permitir que todo extranjero expulsado se dirija a cualquier país que acceda a recibirlo. Esto es así, ya que las garantías del artículo 13 deben leerse conjuntamente con lo dispuesto en el artículo 12.2, sobre el derecho a salir del Estado. Dado que el derecho del artículo 12.2 no está restringido a las personas que se encuentren legalmente dentro del territorio de un Estado, un extranjero que sea expulsado legalmente del país tiene derecho igualmente a elegir el Estado de destino, a reserva de la aceptación de este Estado. Además, no es

\footnotetext{
${ }^{106}$ Zhakhongir Maksudov and Adil Rakhimov, Yakub Tashbaev and Rasuldzhon Pirmatov v. Kyrgyzstan.

107 Observación General Núm. 15, pfo. 10.

108 Ibidem, pfo. 9.

109 Observación General Núm. 32: Artículo 14 Derecho a un juicio imparcial y a la igualdad ante los tribunales y cortes de justicia, CCPR/C/GC/32, pfo. 62.

110 Sholam Weiss v. Austria, CCPR/C/77/D/1086/2002 (2003).

${ }^{111}$ Observación General Núm. 32: Artículo 14 Derecho a un juicio imparcial y a la igualdad ante los tribunales y cortes de justicia, pfo. 62.
} 
Esta revista forma parte del acervo de la Biblioteca Jurídica Virtual del Instituto de Investigaciones Jurídicas de la UNAM www.juridicas.unam.mx

posible negar arbitrariamente al extranjero expulsado la posibilidad de regresar a su propio país. $^{112}$

\section{Privación de libertad y procedimientos de expulsión}

Una cuestión que ha recibido atención es la relativa a la privación de libertad en los casos de expulsión. En diversos precedentes el Comité ha afirmado que la privación de libertad de las personas que se encuentran en situación irregular en el Estado, incluso si son solicitantes de asilo, y que están a la espera de la expulsión no es per se contraria al Pacto. Al afirmar tal legitimidad, el Comité sigue el mismo criterio sostenido por diferentes instancias internacionales. De hecho, si bien existen algunos precedentes en sentido contrario, ${ }^{113}$ decisiones arbitrales de finales del siglo XIX ya admitían la legalidad de la privación de la libertad que se lleva a cabo con vistas a una futura expulsión. ${ }^{114}$ Hoy es generalmente aceptada la legalidad de esa forma de privación de libertad aunque sea sometida a determinados requisitos. También el derecho regional europeo admite la posibilidad de la privación de libertad en estos casos. ${ }^{115}$

Por otra parte, la Relatora Especial sobre los Derechos Humanos de los Migrantes ha aceptado la legalidad de principio de la privación de libertad de los extranjeros que van a ser expulsados, siempre que se cumplieran ciertas condiciones: que la decisión fuera objeto de revisión periódica, que existiera un derecho a recurrir, que la detención

\footnotetext{
${ }^{112}$ Observación General Núm. 27, pfo. 8; Observación General Núm. 15, pfo. 9.

${ }^{113}$ En 1892 el Instituto de Derecho Internacional sostuvo la opinión de que ninguna persona podía ser privada de su libertad por el solo hecho de que estuviera a la espera de una deportación. Institut de Droit International, Règ/es internationales sur l'admission et l'expulsion des étrangers (Rapporteurs: MM. L.-J.-D. Féraud-Giraud, Ludwig von Bar), Session de Genève, 1892.

${ }^{114}$ Grande Bretagne c. Belgique, laudo arbitral del 26 de diciembre de 1898, en De Martens, G. F., Nouveau Recueil Général de Traités et autres actes relatifs aux rapports de Droit International, segunda serie, t. XXIX, Leipzig, Bibilioteca Dietrich Theodor Weicher, 1903; Comisión de Reclamaciones México-Estados Unidos, Daniel Dillon (USA) v. United States, laudo del 3 de octubre de 1928, en U. N., Reports of International Arbitral Awards, t. IV, p. 368. En este caso se aceptó la legalidad de la privación de libertad, aunque se sostuvo que el carácter prolongado de la misma y la ausencia de información al detenido constituían violaciones del derecho internacional.

${ }^{115}$ El artículo 5.1.f del Convenio Europeo establece que es legítima la privación de libertad de una persona contra la cual esté en curso un procedimiento de expulsión, siempre que esta privación de libertad sea conforme a derecho.
} 
Esta revista forma parte del acervo de la Biblioteca Jurídica Virtual del Instituto de Investigaciones Jurídicas de la UNAM

administrativa no tuviera carácter punitivo, que la privación de libertad durara el tiempo estrictamente necesario para que la expulsión se hiciera efectiva y que se pusiera fin a la privación de libertad cuando fuera imposible ejecutar la expulsión por motivos ajenos al extranjero. ${ }^{116}$

Para que la privación de libertad en casos de expulsión sea conforme al Pacto es necesario que se cumplan ciertos requisitos: que ella sea conforme a la ley y no arbitraria (artículo 9.1); que las causas de la privación de libertad sean notificadas al interesado (artículo 9.2), y que la decisión esté sometida a revisión judicial (artículo 9.4). Por otra parte, las condiciones de detención no deben equivaler a un trato prohibido por el artículo 7o., y son de aplicación las garantías del artículo 10 para los casos de privación de libertad.

La primera garantía, que emerge del artículo 9.1 del Pacto, es que la privación de libertad sea conforme al principio de legalidad y no sea arbitraria. Esto fue sostenido por la Corte Internacional de Justicia en el ya citado caso Diallo. La Corte halló una violación del requisito de legalidad necesario a la privación de la libertad (artículo 9.1 del Pacto, semejante al artículo 6o. de la Carta Africana, también citado por la Corte), ya que constató que no se habían respetado las normas internas relativas a la privación de libertad para ejecutar una medida de expulsión. La Corte indicó además que existía una segunda violación de esos mismos artículos, ya que la privación de libertad no sólo había sido ilegal sino también arbitraria. Dijo la Corte que, "en principio, un arresto y una detención que tienen por objetivo ejecutar una decisión de expulsión tomada por la autoridad competente no podrían ser consideradas arbitrarias en el sentido de los textos precitados, incluso si la legalidad de la decisión de expulsión pudiera ser cuestionada". Sin embargo, en el caso la arbitrariedad existía en razón de la gravedad de las irregularidades que habían salpicado las detenciones sufridas por Diallo. ${ }^{117}$

La Corte encontró también una violación del artículo 9.2 del Pacto, ya que Diallo no había sido informado, en el momento de ser arrestado, de las razones de este arresto. La

\footnotetext{
${ }^{116}$ Rodríguez Pizarro, Gabriela, Migrant Workers, Report of the Special Rapporteur Ms. Gabriela Rodriguez Pizarro, submitted pursuant to Commission on Human Rights resolution 2002/62, E/CN.4/2003/85, 2002, pp. $12-64$.

${ }^{117}$ Affaire Ahmadou Sadio Diallo (République de Guinée c. République démocratique du Congo), pfos. 81 y 82.
} 
Esta revista forma parte del acervo de la Biblioteca Jurídica Virtual del Instituto de Investigaciones Jurídicas de la UNAM

Corte señaló sin embargo que no había existido violación de este mismo artículo en cuanto exige que se notifique la acusación formulada contra la persona que es arrestada, ya que este pasaje del artículo se aplica solamente en casos de arresto vinculados a procesos penales. La Corte rechazó, por falta de pruebas, la alegación de Guinea relativa a los presuntos malos tratos sufridos por Diallo durante su privación de libertad (artículo 10.1 del Pacto, sobre trato a las personas privadas de la libertad, artículo 7o. del Pacto sobre tratos prohibidos y artículo 5o. de la Carta Africana sobre respeto a la dignidad humana, además de la fuente consuetudinaria que prohíbe los tratos crueles, inhumanos o degradantes). ${ }^{118}$

El Comité ha seguido un criterio parecido. En A. C. Australia (caso relativo a un solicitante de asilo camboyano) se afirmó que la privación de libertad de los demandantes de asilo no es per se contraria al Pacto ni al derecho consuetudinario. Sin embargo, es necesario que el Estado justifique la necesidad de la privación de libertad en el caso concreto, y que esta necesidad sea revisada en forma periódica, de modo que la privación de libertad no se mantenga más allá del tiempo estrictamente necesario. En el caso, una privación de libertad de casi cuatro años se consideró violatoria del artículo 9.1. También se declaró una violación del artículo 9.4, ya que si bien existía la posibilidad de revisión judicial, ésta se limitaba a un control meramente formal acerca de que la persona privada de libertad era una de las personas a las que el derecho interno permitía privar de libertad. ${ }^{119}$

En la misma línea de la decisión citada, existe un importante corpus de decisiones del Comité sobre la privación de libertad de migrantes en Australia. En todos estos casos se ponía en cuestión la ley australiana que ordena de modo general que todos los extranjeros en situación irregular sean privados de su libertad, sin una evaluación individualizada de cada caso. En las respectivas decisiones, aunque el Comité recuerda que la detención en el curso de los procedimientos migratorios no es de por sí arbitraria, considera que cualquiera que sea el motivo inicial de privación de libertad el Estado no puede mantenerla de modo indefinido sin un motivo concreto e individualizado. Para

\footnotetext{
${ }^{118}$ Affaire Ahmadou Sadio Diallo (République de Guinée c. République démocratique du Congo).

${ }^{119}$ A. v. Australia, CCPR/C/59/D/560/1993 (1997). El denunciante alegaba también que el artículo 9.4 lleva implícito el derecho a la asistencia legal que, según decía, le había sido denegada. El Comité afirmó, como cuestión de hecho, que no le había sido negada la asistencia legal.
} 
Esta revista forma parte del acervo de la Biblioteca Jurídica Virtual del Instituto de Investigaciones Jurídicas de la UNAM

evitar la tacha de arbitrariedad prohibida por el artículo 9.1, la privación de libertad debe considerar los factores relevantes caso por caso y estar sometida a revisiones periódicas. ${ }^{120}$

En los mismos casos se afirmaba la existencia de una violación del artículo 9.4, ya que la privación de libertad, en razón de la ausencia de bases individuales, no podía ser recurrida ante los tribunales. El Comité, a la vista de los precedentes de la Corte Suprema australiana que reconocen la constitucionalidad de la detención indefinida de inmigrantes, afirmó la existencia de tal violación. ${ }^{121}$

Por supuesto, la violación del artículo 9.1 es independiente de la del artículo 9.4, como tuvo ocasión de señalar el Comité en un caso contra Canadá en el que a pesar de considerar que la privación era legal y no arbitraria, encontró que la revisión judicial había durado un tiempo excesivo. ${ }^{122}$ Inversamente, en un caso contra Kirguistán se halló una violación del artículo 9.1 sin violación del artículo 9.4 del Pacto. ${ }^{123}$

La detención de menores en vista a una futura deportación, siempre que sea legal y no arbitraria, no es per se contraria ni al artículo 9o. (sobre condiciones de privación de libertad) ni al artículo 24 (protección de la infancia). ${ }^{124}$ Sin embargo, en caso de arbitrariedad, y teniendo en cuenta las circunstancias del caso, además de una violación del artículo 9 puede haber una violación del artículo 24 del Pacto en cuanto obliga a considerar siempre el interés superior del menor. ${ }^{125}$

En cuanto al artículo 9.2, en el caso F. K. A. G. et al. C. Australia, los denunciantes se quejaban de que ninguno de ellos había sido informado de los motivos de su detención. En el caso de la mayoría de ellos, el Comité consideró que la información que se les

\footnotetext{
${ }^{120}$ C. v. Australia. Omar Sharif Baban v. Australia, CCPR/C/78/D/1014/2001 (2003); Ali Aqsar Bakhtiyari and Roqaiha Bakhtiyari v. Australia. Kwok Yin Fong v. Australia, CCPR/C/97/D/1442/2005 (2009); M. M. M. et al. v. Australia, CCPR/C/108/D/2136/2012 (2013). F. K. A. G. et al. v. Australia, CCPR/C/108/D/2094/2011 (2013).

${ }^{121}$ C. v. Australia. Omar Sharif Baban v. Australia. Ali Aqsar Bakhtiyari and Roqaiha Bakhtiyari v. Australia. Kwok Yin Fong v. Australia. M. M. M. et al. v. Australia. F. K. A. G. et al. v. Australia.

122 Mansour Ahani v. Canadá.

${ }^{123}$ Zhakhongir Maksudov and Adil Rakhimov, Yakub Tashbaev and Rasuldzhon Pirmatov v. Kyrgyzstan.

124 Samba Jalloh v. Netherlands, CCPR/C/74/D/794/1998 (2002).

${ }^{125}$ Ali Aqsar Bakhtiyari and Roqaiha Bakhtiyari v. Australia.
} 
había dado inicialmente (que eran detenidos en razón de su irregularidad migratoria) era suficiente. Sin embargo, respecto de un subgrupo que había tenido un visado especial (luego revocado), la razón de la detención había sido el posterior informe de inteligencia que recomendaba denegar la protección internacional. Dado que los interesados no habían podido acceder al contenido de este informe, el Comité declaró la existencia de una violación del artículo 9.2. ${ }^{126}$

De conformidad con lo que habían pedido los autores, el Comité declaró también que el carácter arbitrario de la detención, su duración indefinida, el desconocimiento de derechos procesales de los detenidos y las duras condiciones de detención habían infligido un importante daño psicológico a los detenidos y constituían un trato prohibido por el artículo 7o. Habida cuenta de esta conclusión, el Comité consideró innecesario analizar la cuestión a la luz del artículo 10, sobre las condiciones de privación de la libertad.

De modo parecido, en el ya mencionado Madafferi c. Australia, se consideró que la privación de libertad estaba justificada en concreto, y por lo tanto no había violación del artículo 9.1. Sin embargo, dado que el reingreso en prisión en contra del criterio médico y tras un periodo de prisión domiciliaria agravó la salud mental de Madafferi, el Comité halló una violación del artículo 10.1, que establece la obligación de respetar la dignidad de las personas privadas de su libertad. ${ }^{127}$

\section{CONCLUSIONES}

En el presente artículo hemos abordado la cuestión de la expulsión de extranjeros a la luz del Pacto Internacional de Derechos Civiles y Políticos. Para ello nos hemos basado fundamentalmente en los precedentes del Comité de Derechos Humanos forjados a partir de comunicaciones individuales, así como en sus observaciones generales. También hemos mencionado un importante caso resuelto por la Corte Internacional de Justicia.

Todos estos precedentes marcan una línea interpretativa bastante consistente en relación con las normas del Pacto. Dada la actualidad de los debates en torno de la

\footnotetext{
${ }^{126}$ F. K. A. G. et al. v. Australia.

127 Francesco Madafferi v. Australia.
} 
Esta revista forma parte del acervo de la Biblioteca Jurídica Virtual del Instituto de Investigaciones Jurídicas de la UNAM

cuestión migratoria, es de esperar que este corpus de precedentes internacionales continúe incrementándose.

En lo que se refiere a los límites sustantivos a la expulsión, el Comité realiza una interpretación coherente del Pacto, que impide la expulsión en casos de riesgo a la vida o riesgos de tortura o tratos análogos. Sobre un punto fundamental, sin embargo, la jurisprudencia del Comité es oscilante: no queda claro cuál es el nexo que debe haber entre la expulsión y el riesgo a la vida y a la integridad para que aquélla resulte prohibida. Igualmente, en materia de derecho a la vida familiar, el Comité se esfuerza en poner en funcionamiento un test de equilibrio entre las razones alegadas por el Estado para la expulsión y la intensidad de los vínculos familiares que son interrumpidos. La casuística de la realidad parece sin embargo sobrepasar los estrechos límites de un criterio abstracto.

En cuanto a los límites procesales a la expulsión, la jurisprudencia del Comité se refuerza con la mencionada sentencia de la Corte Internacional de Justicia. En general, parece que las interpretaciones de ambos órganos internacionales van en el mismo sentido. Los precedentes del Comité son por supuesto abundantes, y se refieren a una casuística más amplia.

En lo relativo a los criterios del Comité, aunque sus interpretaciones son técnicamente consistentes, parece evidenciarse cierta facilidad para aceptar la privación de libertad sobre la sola base de la irregularidad migratoria, aunque luego esa privación de libertad se evalúe con mayor rigidez desde otros ángulos (como la justificación de su permanencia o la disponibilidad de la revisión judicial). Quizá en un futuro el Comité torne su criterio más estricto. 